\title{
An environmental justice analysis of exposure to traffic-related pollutants in England and Wales
}

\author{
J. H. Barnes \& T. J. Chatterton \\ Air Quality Management Resource Centre, \\ University of the West of England, UK
}

\begin{abstract}
In 2003, Mitchell and Dorling undertook the first national level environmental justice analysis of air quality in Britain and established that there were clear inequalities in exposure to air pollution based on demography, poverty and car ownership. This paper updates and improves on their work looking at relationships between emissions and exposure a decade later. Using 2011 pollution data $\left(\mathrm{NO}_{2}\right.$ concentrations and NOx emissions from road transport) in combination with socio-economic and demographic data from the UK Census, we present analyses of patterns of exposure at the level of small area census units. Then, using an enhanced version of the UK Department for Transport's annual vehicle safety inspection records, we spatially attribute the annual NOx emissions for private motor vehicles to the location of each vehicle's registered keeper. From this, it is possible to identify who are the highest emitters of traffic related pollution and to explore the relationships between responsibility for causing emissions and exposure to pollution. The research focuses on England and Wales and finds that despite a decade of efforts to reduce air pollution, significant inequalities still characterise exposure. Young children and adults, and households in poverty are much more likely to suffer from the effects of traffic than older people and more affluent households. Furthermore, it is these more affluent households that contribute most to traffic pollution through owning the most vehicles and generating the highest emissions.
\end{abstract}

Keywords: environmental justice, air pollution, emissions, transport, exposure, MOT, census, demographic, car ownership, poverty. 


\section{Introduction}

Air pollution is a significant issue in cities globally. In 2014 the World Health Organisation (WHO) [1] declared that air pollution is now the world's largest single environmental health risk, with ambient (outdoor) air pollution causing 3.7 million deaths annually. Road traffic is the major contributor to local ambient air pollution and is largely responsible for elevated concentrations of nitrogen dioxide $\left(\mathrm{NO}_{2}\right)$, among other pollutants. In 2014, UK road vehicles were estimated to contribute $32 \%$ to total UK NOx emissions, including 23\% from passenger cars and LDVs (Wakeling et al. [2]). In Europe, exceedences of the Ambient Air Quality Directive (AAQD) (2008/50/EC) annual mean limit values for nitrogen dioxide, derived from WHO health-based thresholds, are widespread, including across the UK. In 2010, when the annual mean limit value for $\mathrm{NO}_{2}$ was supposed to be achieved (and five years after its own parallel domestic $\mathrm{NO}_{2}$ objectives should have been met), the UK was in breach for $93 \%$ of its designated zones and agglomerations. Most recent estimates from the Department for the Environment, Food and Rural Affairs (Defra) [3], which is responsible for compliance reporting against the AAQD to the European Commission (EC), were that exceedences would continue until at least 2025 in some urban areas, risking substantial fines under the infraction proceedings that the EC [4] launched against the UK Government in February 2014.

The ambient air quality objectives and limit values set out in UK and EU legislation are derived from health-based standards, originally published by WHO in 1987 and subsequently revised and interpreted by UK advisory groups such as the Committee on the Medical Effects of Air Pollution (COMEAP). In a recent review of the growing body of epidemiological and mechanistic evidence, COMEAP [5] stated that while $\mathrm{NO}_{2}$ is a marker for the effects of other trafficrelated pollutants, it is likely that it is also a cause of additional health impacts. Furthermore, evidence suggests that, similarly to fine particulates, $\mathrm{NO}_{2}$ is a nonthreshold pollutant (Jarvis et al. [6]) indicating that health effects are experienced at concentrations below the WHO standards and the existing EU limit values and national ambient air quality objectives. Based on recommendations from COMEAP, Defra [7] have revised its estimates of the UK annual equivalent attributable deaths for both $\mathrm{PM}$ and $\mathrm{NO}_{2}$ to 44,750-52,500 with an associated social cost in the range $£ 25.3 \mathrm{bn}-£ 29.7 \mathrm{bn}$. With $81.5 \%$ of the 2011 population of England and Wales living in urban areas (ONS [8]), the potential for acute and chronic effects of traffic-related pollutants, including $\mathrm{PM}$ and $\mathrm{NO}_{2}$, are therefore significant.

Exposure to traffic-related air pollution and likely health impacts, are unequally distributed across populations both spatially, and in terms of demographic groupings (Gegisian [9]). While the statistics quoted above relate to average statistical mortality, this covers a broad range, with the most vulnerable groups (children, the elderly and those with pre-existing health conditions) being much more susceptible to the effects of air pollution than others. Urban areas have the highest concentrations of traffic-related pollution, but there is significant local variation even within cities and towns. As Mitchell and Dorling [10] identified in 
the first national, spatial (ward level) analysis of air pollution exposure, these inequalities lead to significant social and environmental justice issues in Britain, with children and young adults and households in poverty more likely to be exposed to higher concentrations of $\mathrm{NO}_{2}$. This is particularly important given the vulnerability of children and the negative effect that early exposure to air pollution is likely to have throughout their lives. Households in poverty too are also likely to suffer the 'triple-jeopardy' effect of poor ill-health (1) as a consequence of their socio-economic circumstances (2) being further exacerbated by air pollution (3) (Jerrett et al. [11]). To compound the injustice, Mitchell and Dorling [10] also found that those areas with the highest concentrations of $\mathrm{NO}_{2}$ were also those areas with the lowest levels of car ownership, suggesting that some of the poorest households are being unfairly affected by the emissions of other, often wealthier, road users.

This paper updates and improves on the environmental justice and air pollution work of Mitchell and Dorling [10] in four main ways. Firstly by using recent air pollution data for 2011 ( $\mathrm{NO}_{2}$ concentrations and road NOx emissions). Secondly, using socio-economic and demographic data from the 2011 UK Census, to present analyses of patterns of exposure at the level of small area census units (Mitchell and Dorling had used 1991 Census data in the absence of available results from the 2001 Census at time of publication). Thirdly, undertaking the analysis at a finer spatial resolution, using Lower-layer Super Output Areas (mean households 700) as opposed to wards (mean households $\sim 6,600$ ). Fourthly, through a novel analysis of the Department for Transport's annual vehicle safety inspection (formerly the 'MOT' (Ministry of Transport) test) digital dataset we calculate the average NOx emissions per household in each area on the basis of mileage readings from all individual private vehicles in the UK ( $\sim 30$ million), to identify who are the highest emitters of traffic related pollution.

\section{Data and methodology}

\subsection{Study area and scale of analysis}

Based on the availability of consistent geographies for the 2011 UK Census data, the study area for this research is England and Wales. The geographical unit of enquiry is the Lower-layer Super Output Area (LSOA). These are areas developed for the UK Census in England and Wales. These areas have an average population of $\sim 700$ households and $\sim 1600$ people (minimum size of 1,000 residents, or 400 households, maximum population of 3,000 residents or 1,200 households). In total there are 34,753 LSOAs in the 2011 Census in England and Wales. Their design is intended to make them reasonably compact, and to allow significant social homogeneity within each area. LSOAs are also smaller than the ward-level geography ( $\sim 8500$ in Britain) used by Mitchell and Dorling, therefore this paper not only provides a temporal update, but also presents a much finer spatial resolution analysis of the relationship between air pollution and census variables. 


\subsection{Census data}

Following Mitchell and Dorling, air pollution data were analysed against socioeconomic and demographic data from the UK Census. 2011 InFuse Census data were downloaded from UK Data Service Census Support (http://infuse2011.mimas.ac.uk) (ONS [12]) for all LSOAs in England and Wales. Data were analysed using $\mathrm{R}$ (version 3.2.3) (R Core Team [13]) by producing quantile plots to explore the relationship between variables based on the whole study area population.

\subsubsection{Demographic analysis}

Demographic Census data were used to calculate the number of people in each LSOA within each of 13 age bands ( $<1$ year, 1-4 years, 5-9 years, 10-14 years, 15-19 years, 20-24 years, 25-34 years, 35-44 years, 45-54 years, 55-64 years, 65-74 years, 75-84 years, 85+ years). Using R, each age band was divided into deciles, with upper deciles representing the greatest proportion of people in a specified age band.

\subsubsection{Poverty data and analysis}

Historically, poverty has been measured either indirectly, in terms of a lack of resources (e.g. income), or directly, as the consequences of that lack of resources on standards of living (e.g. deprivation). Definitions and distinctions may not be consistent over time or space and therefore it is essential that research referring to poverty metrics utilises the most appropriate measure.

From a review of previous studies on social justice and air pollution and an investigation of other available datasets, a range of potential indicators of poverty were identified that might be suitable for the study. In addition to the measure of poverty used in the analyses within this paper and described below, the data were also tested using median household income estimates produced by social data company Experian [14], and the 2010 English Indices of Deprivation (IMD) published by the Department for Communities and Local Government (DCLG) [15]. Whilst these showed very similar results, issues regarding the quality and spatial coverage of these datasets meant that they were not selected for presentation. Ultimately, a decision was made to use a measure of the percentage of households in poverty developed from the Breadline Britain Index by the Poverty and Social Exclusion (PSE) Unit at University of Bristol (http://www.poverty.ac.uk). Not only was this approach unhindered by the geographical constraints posed by the income and IMD datasets, but it allowed for greater consistency with the previous Mitchell and Dorling study.

The Breadline Britain Index (BBI) was developed by Gordon and Pantazis [16] from an individual and household level analysis of data from the Breadline Britain survey in 1990. It allows the percentage of households in poverty ('Below the Breadline') in any area to be calculated using variables available from census data relating to factors such as housing tenure, employment, health, household composition. The survey for generating the BBI was undertaken again in 1999 by PSE to establish a new set of variables for use with the 2001 Census to reflect changing patterns of poverty. 
The updated poverty indicator was calculated by summing the following parameters for each LSOA (Dorling et al. [17]):

- $57.6 \%$ of overcrowded households (more than one person per room)

- $35.7 \%$ of households renting from local authorities or housing associations

- $32.4 \%$ of lone-parent households

- $30.3 \%$ of households with an unemployed Household Reference Person (HRP)

- $18.4 \%$ of households with no car

- $16.5 \%$ of households renting from private landlords

- $16.1 \%$ of households with a member with a limiting long-term illness

- $13.5 \%$ of households with no central heating or without sole use of amenities

- $11.3 \%$ of households with HRP in a low social class (as defined under the National Statistics Socioeconomic Classification (NS-SEC) levels 6, 7 or 8: semi-routine occupations, routine occupations and long-term unemployed/ never worked - see Rose and Pevalin [18]).

For this analysis, these same coefficients were used with 2011 Census data (although no data was collected in the 2011 Census on households without sole use of amenities). Although some caution needs to be applied in using the 1999 coefficients with 2011 Census data due to the changing nature of poverty in the UK, further discussion with academics involved in the creation of the index concluded that this was the best data/method currently available (Dorling [19]).

\subsubsection{Car availability analysis}

Availability data for cars and vans from the 2011 UK Census was used to calculate the percentage of households in each LSOA within the following bands: households with access to no car/van, households with access to 1 car/van, households with access to 2 cars/vans, households with access to 3 cars/vans, households with access to $3+$ cars/vans. Using R, the car availability data were placed into deciles sorted by increasing car ownership.

\subsection{Pollution data and analysis}

Annual mean UK background pollutant-based csv files $\left(\mathrm{NOx}\right.$ as $\left.\mathrm{NO}_{2}\right)$ for 2011 were downloaded from the Defra website: (http://uk-air.defra.gov.uk/data/pcmdata) and 2011 NOx UK emissions data were downloaded as ASCII files from the UK National Atmospheric Emissions Inventory (NAEI) website (http://naei.defra.gov.uk/data/map-uk-das). Using ArcGIS (10.3) the ASCII files were converted to raster and then to point vector data. Both the $\mathrm{NO}_{2}$ concentration and NOx emissions data are provided on a $1 \mathrm{~km}^{2}$ grid resolution and are part of the UK government's compliance assessment reporting against the AAQD (2008/50/EC). Due to variations in population density, LSOAs vary in size with some covering multiple $1 \mathrm{~km}^{2}$ grid cells and others contained within a single grid cell. $\mathrm{NO}_{2}$ concentrations were attributed to LSOAs by area-weighting based on the proportion of the LSOA that intersects with each $1 \mathrm{~km}^{2}$ areal grid cell to ensure concentrations are proportionally averaged across each LSOA. NOx emissions were attributed on the basis of the proportion of the grid cells that are intersected 
by the each LSOA in order to present the data in a comparable way across LSOAs i.e. by $\mathrm{km}^{2}$. In the absence of data to show sub-area variability it was assumed that averaged concentrations and emissions were uniform over both each individual grid cell and each LSOA.

\subsection{Private vehicle emissions data and analysis}

In 2010, the UK Department for Transport began publishing the records from the annual vehicle roadworthiness inspections (known in the UK as 'MOT' tests). These tests are required for every vehicle over three years old. This data provides details of the make and model of each vehicle, engine size, fuel type, date of first registration and colour, along with the recorded mileage at each test. Using the latter, it is possible to estimate the annual mileage of each vehicle and from this to calculate the total and average NOx emissions for all private vehicles registered within each LSOA. This methodology is described in more detail in another paper in this volume (Chatterton and Barnes [20]).

\section{Results}

Figure 1 depicts average annual mean $\mathrm{NO}_{2}$ concentrations across age categories, based on LSOA rather than ward areas and using 2011 rather than 1991 census and 2011 rather than 2001 pollution data. The plot shows a strikingly similar pattern to the original Mitchell and Dorling plot. Although pollutant concentrations have fallen (by $\sim 10 \mu \mathrm{g} / \mathrm{m}^{3}$ ) between the two plots, based on the Defra data (potential issues with the accuracy of this are described in the next section), the relative exposure of the different age categories remains very similar to a decade ago. Areas with a high proportion of children under 5 years and young adults (20-44 years) have higher concentrations of annual mean $\mathrm{NO}_{2}$. Conversely, areas with a greater proportion of adults over 45 years have lower $\mathrm{NO}_{2}$ concentrations. The greatest differentials appear to be in the 20-24 and the 55-64 age groups, as borne out in Figure 2.

Figure 2 further demonstrates the variation in exposure by age by examining the ratios between the upper and lower deciles in each age category. The data presented here relate both to $\mathrm{NO}_{2}$ concentrations and $\mathrm{NOx}$ emitted from road transport within each LSOA. Again, these plots reproduce Mitchell and Dorling's findings that there is a clear disparity in exposure to air pollution between young children and young adults compared with older children and older adults. As Mitchell and Dorling suggested, this may be a reflection of younger (poorer) versus older (more affluent) families and the consequent ability of the latter to choose less polluted residential locations. Using the improved and updated data in this study, this differential appears to have increased: LSOAs with a high proportion of young adults have $\mathrm{NO}_{2}$ concentrations that are twice as high as the average and NOx emissions that are almost five times higher. Given that NOx emissions are perhaps a better representation than $\mathrm{NO}_{2}$ concentrations of the full health and social impacts of motor vehicles, this is a significant finding. 

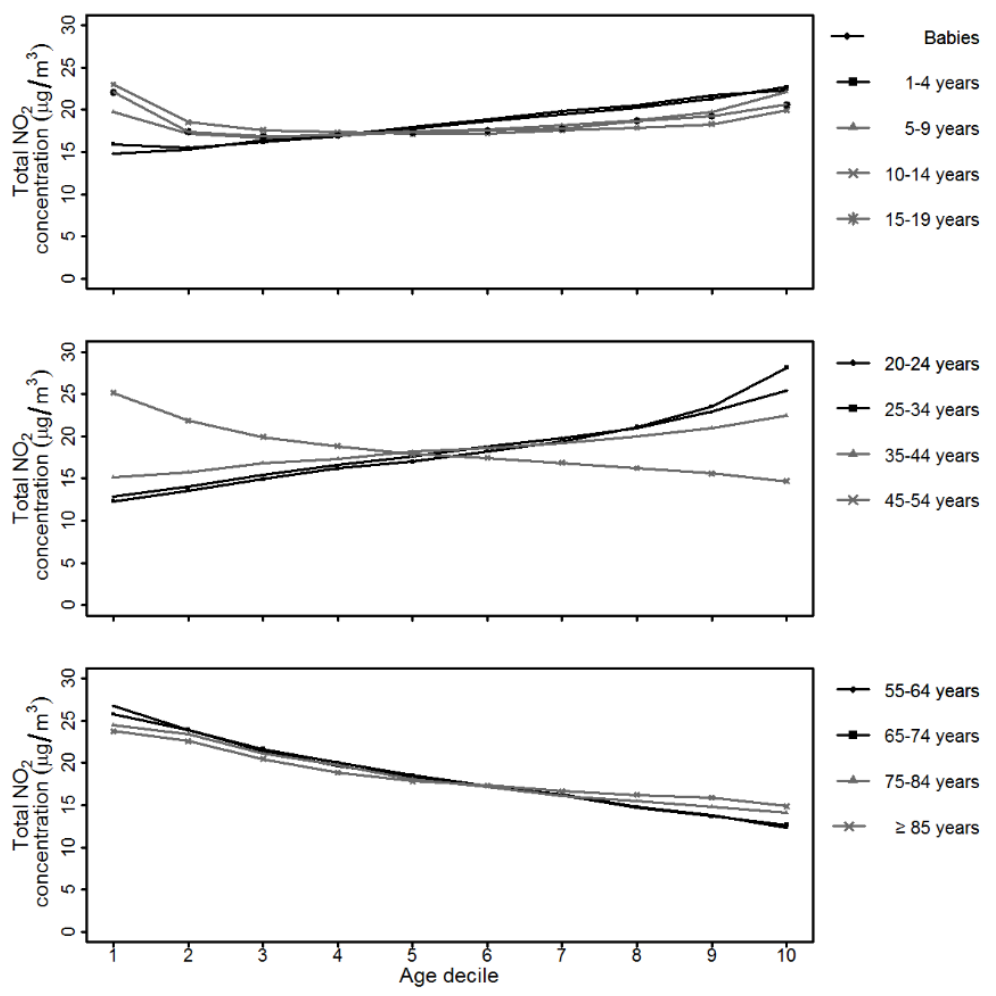

Figure 1: Annual mean $\mathrm{NO}_{2}$ concentration by specified age decile groups for England and Wales.
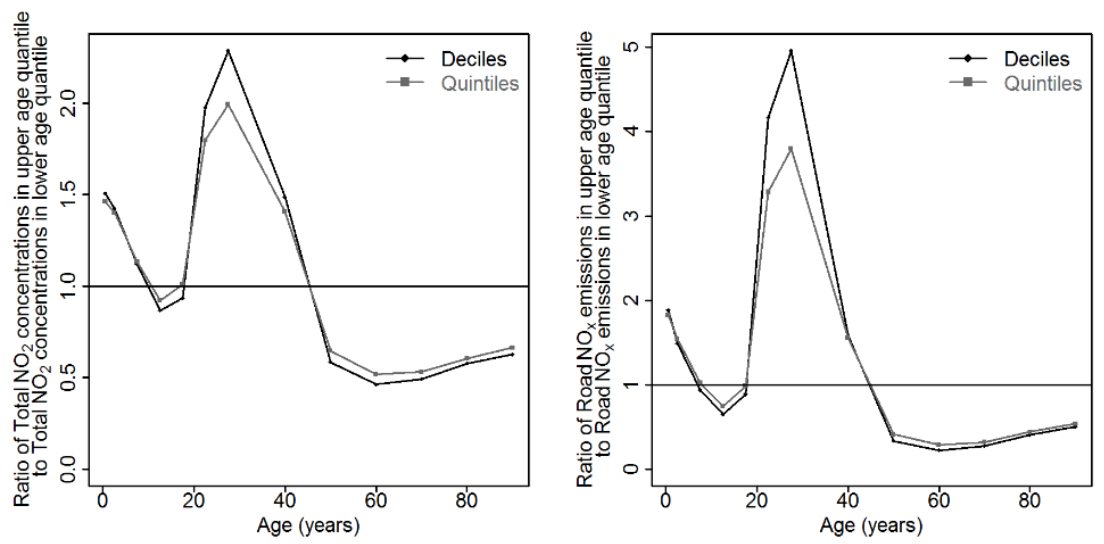

Figure 2: Annual mean $\mathrm{NO}_{2}$ concentrations (left) and road NOx emissions (right) by upper to lower age ratio deciles and quintiles. 

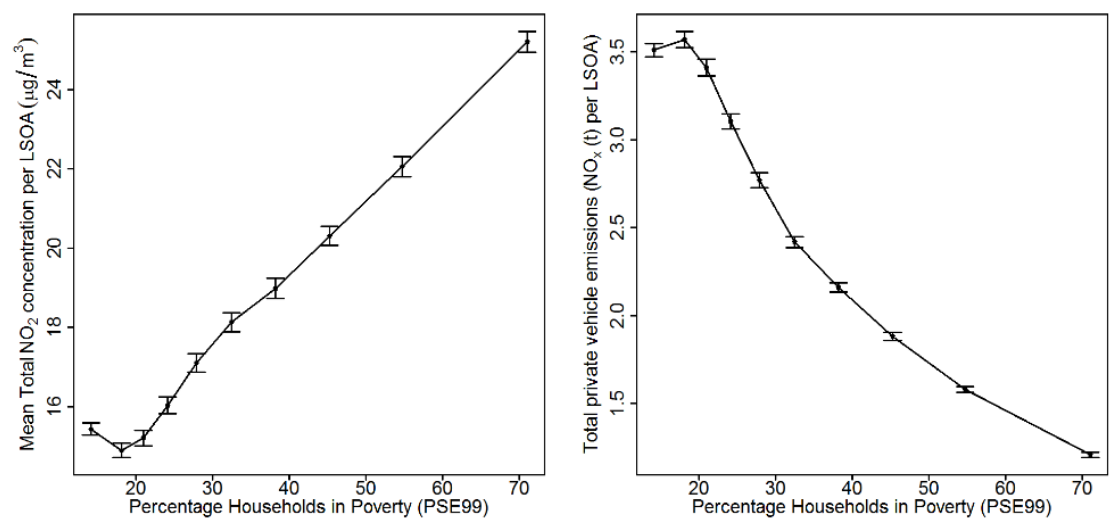

Figure 3: Percentage households in poverty against annual mean $\mathrm{NO}_{2}$ concentrations (left) and total private vehicle NOx emissions (right). Error bars indicate $95 \%$ confidence intervals (CIs).

Figure 3 presents the annual mean $\mathrm{NO}_{2}$ concentrations (left) and total private vehicle NOx emissions (right) by the percentage of households in poverty. The right hand plot is based on emissions data derived from the MOT dataset and therefore represents the total emissions from private motor vehicles registered to households within each LSOA irrespective of where they are emitted. The plot on the left represents the concentrations to which households in each LSOA are exposed, irrespective of who is emitting them.

As found previously by Mitchell and Dorling, there is a strong positive relationship between levels of poverty and $\mathrm{NO}_{2}$ concentrations, indicating that the higher the proportion of households within an LSOA that are in poverty, the more likely they are to be exposed to higher concentrations of air pollution (Figure 3 left). This also holds true for PM, although space isn't not afforded here to present these results. The slight 'kick-up' in the lowest poverty decile was also present in Mitchell and Dorling's earlier analysis. However, either through changes in pollution, shifting patterns of poverty or changes in the data and level of spatial aggregation we have used (to be the subject of further investigation), this kick has become much less pronounced. The kick indicates that the areas with the lowest levels of poverty are exposed to marginally higher $\mathrm{NO}_{2}$ concentrations than in the next decile. This potentially reflects an increase in wealthy city-dwellers, through the 'urban renaissance' and increasing gentrification of inner-city areas (Atkinson [21]). The plot on the right, however, shows a clear negative relationship between generation of emissions and poverty, indicating that those in the highest poverty decile produce the lowest NOx emissions and vice versa.

The strength of the relationship demonstrated in the left hand plot on its own indicates very significant environmental justice issues in relation to exposure to pollution. However, when the right hand plot is taken into account as well, indicating that much of the pollution that poorer areas are exposed to is generated 
by people living elsewhere, often in wealthier areas, then these justice issues are further compounded.

To further examine responsibility for causing emissions, Mitchell and Dorling explored the relationship between household car ownership and exposure to pollution. The plots in Figure 4 update their analysis, but still show that those areas in the UK with lower car ownership/access are those that are exposed to the greatest concentrations of pollution, and conversely those with highest ownership/access are exposed to the lowest concentrations.
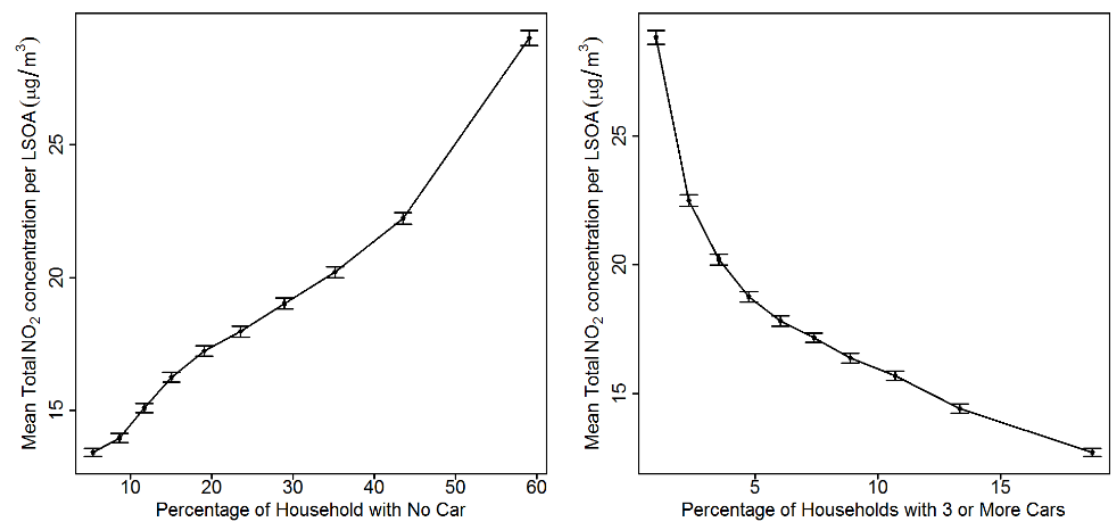

Figure 4: Annual mean $\mathrm{NO}_{2}$ concentrations against percentage of households with no car (left) and with three or more cars (right). Error bars indicate $95 \%$ CIs.

\section{Discussion}

This paper presents a ten-year update on the first national environmental justice research on air quality in the UK (including a 20-year update on the census data used). Its purpose is to investigate whether the findings of the original study are still relevant, based on more recent census and pollution data, and how our analysis can contribute to the conversation.

Like Mitchell and Dorling [10], this research examined the relationships between the exposure of the populations of England and Wales to $\mathrm{NO}_{2}$ by age, level of poverty and car ownership. Further insight was provided through the presentation of results in the context of NOx emissions from road transport from the UK NAEI and the use of new data from the UK 'MOT' dataset. The latter enabled representation of the NOx emissions generated by people living in the area, rather than by vehicles passing through. By improving the spatial resolution of the analysis approximately four-fold, from ward level to LSOA, this research makes the relationships identified much more robust.

It is acknowledged that areal analysis, even using these relatively homogeneous spatial areas, does not reflect sub-area variations in pollution and population characteristics. There is also an assumption that pollution concentrations in each 
LSOA are representative of population exposure, although residents may spend much of their time outside of their residential LSOA working, commuting, in education or participating in other activities. This assumption is, however, in line with UK policy which considers that residential location should be the 'relevant receptor' for the assessment of exposure to annual mean pollution concentrations (Defra [22]). Furthermore, the analysis is dependent on the quality of the data utilised. Whilst the government-sourced $\mathrm{NO}_{2}$ and $\mathrm{NOx}$ data are the only national datasets available and are used for compliance reporting to the European Commission, there are acknowledged questions over the validity of the underlying emission factors (which also underpin the MOT emissions data) due to inconsistencies between type-approval tests and real-world emissions (DfT [23]; Williams [24]). Thus, the $\mathrm{NO}_{2}$ and $\mathrm{NOx}$ data reported here are likely to significantly underestimate actual concentrations and emissions. This is particularly relevant when considering the reduction in absolute concentrations over the last decade suggested by the data (highlighted above with regard to Figure 2).

\section{Conclusion}

The work presented in this paper demonstrates that social inequalities with respect to air pollution are clearer and stronger than identified over a decade ago by Mitchell and Dorling [10]. It is uncertain the extent to which this is a reflection on the improved accuracy and relevance of the data we have used or whether the patterns of inequality have strengthened over the intervening decade. However, the fact that the environmental justice problems of a decade ago are still extant and potentially worsening should be of significant concern. This is particularly the case with regard to greater exposure of very young children who are the most susceptible to health impacts from air pollution. Younger generations and those in poverty have less control over where they live, and whilst this may partially be the cause of the inequalities identified, it should not be the case that this is just taken to be a fact of life. It is evident that governments in the UK and elsewhere in Europe are experiencing difficulties in being able to reduce traffic-related air pollution, and this research, by highlighting air pollution as a social as well as an environmental issue, makes a valuable and timely contribution to an important debate.

\section{Acknowledgements}

The work has been undertaken under EPSRC Grant EP/K000438/1. Grateful thanks to members of DfT, VOSA, DVLA and DECC, Dr Paul White at UWE, and Professor David Gordon at the University of Bristol and Professor Danny Dorling at the University of Oxford. We would particularly like to acknowledge other members of the MOT project team: Prof. Jillian Anable, Dr Sally Cairns, Prof. Eddie Wilson, Dr Oliver Turnbull, Simon Ball and Paul Emmerson.

Contains National Statistics and Ordnance Survey data (C) Crown copyright and database right 2012. MOT Project website www.MOTproject.net 


\section{References}

[1] WHO. 7 million premature deaths annually linked to air pollution, News release, http://www.who.int/mediacentre/news/releases/2014/air-pollution/ en/, 2014.

[2] Wakeling, D., Passant, N.R., Murrells, T.P., Pang, Y., Thistlethwaite, G., Walker, C., Garcia, J.M.R., Webb, J., Brown, P., Del Vento, S., Misra, A., (Ricardo Energy \& Environment) Hobson, M., Pridmore, A., Dore, C., (Aether) Misselbrook, T., (Rothamsted Research), UK Informative Inventory Report (1990 to 2014), 13/03/2016, http://naei.defra.gov.uk/ reports/reports?report_id=896, 2016.

[3] Defra, Improving air quality in the UK, Tackling nitrogen dioxide in our towns and cities, UK overview document, https://www.gov.uk/ government/uploads/system/uploads/attachment_data/file/486636/aq-plan2015-overview-document.pdf, 2015.

[4] European Commission, Press Release Database, Brussels, 20 February 2014, http://europa.eu/rapid/press-release_IP-14-154_en.htm, 2014.

[5] COMEAP. Statement on the evidence for the effects of nitrogen dioxide on health, https:/www.gov.uk/government/uploads/system/uploads/ attachment_data/file/411756/COMEAP_The_evidence_for_the_effects_of nitrogen_dioxide.pdf, 2015.

[6] Jarvis D.J., Adamkiewicz G., Heroux M.E., Rapp, R. and Kelly, F.J., Nitrogen dioxide. In: WHO Guidelines for Indoor Air Quality: Selected Pollutants. Geneva: World Health Organization; 2010. 5. Available from: http://www.ncbi.nlm.nih.gov/books/NBK138707/ [Accessed 21 February 2016].

[7] Defra, Valuing impacts on air quality: Updates in valuing changes in emissions of Oxides of Nitrogen (NOx) and concentrations of Nitrogen Dioxide $\left(\mathrm{NO}_{2}\right)$, https:/www.gov.uk/government/uploads/system/uploads/ attachment_data/file/460401/air-quality-econanalysis-nitrogen-interimguidance.p $\overline{d f}, 2015$.

[8] Office for National Statistics, 2011 Census Analysis - Comparing Rural and Urban Areas of England and Wales, http://www.ons.gov.uk /ons/dcp171776_337939.pdf, 2013.

[9] Gegisian, I., Grey, M., Irwin J \& Longhurst, J.W.S., Environmental justice consequences of the UK's local air quality management (LAQM) system. In Longhurst, J.W.S. \& Brebbia, C.A. (Editors) Air Pollution XIV. WIT Press. Southampton and Boston. pp. 175-183, 2006.

[10] Mitchell, G., \& Dorling, D., An environmental justice analysis of British air quality. Environment and Planning A, 35(5), 909-929, 2003.

[11] Jerrett, M., Burnett, R.T., Kanaroglou, P., Eyles, J., Finkelstein, N., Giovis, C., \& Brook, J.R., "A GIS - Environmental justice analysis of particulate air pollution in Hamilton, Canada" Environment and Planning A, 33(6) 955-973, 2001.

[12] Office for National Statistics, 2011 Census: Aggregate data (England and Wales) [computer file]. UK Data Service Census Support. Downloaded 
from: http://infuse.mimas.ac.uk. This data is licensed under the terms of the Open Government Licence [http://www.nationalarchives.gov.uk/doc/opengovernment-licence/version/2

[13] R Core Team, $R$ : A Language and Environment for Statistical Computing, $R$ Foundation for Statistical Computing, Vienna, Austria, https://www.Rproject.org, 2016.

[14] Experian, Household Income 2011, Data Profile, UK Data Archive Study Number 5738 - Experian Demographic Data, 2004-2011 http://doc.uk dataservice.ac.uk/doc/5738/mrdoc/pdf/5738_household-income_2011.pdf, 2011.

[15] Department for Communities and Local Government, English Indices of Deprivation 2010, https://data.gov.uk/dataset/index-of-multipledeprivation

[16] Gordon, D. \& Pantazis, C., Breadline Britain in the 1990s, Aldershot, Ashgate, 1997.

[17] Dorling, D., Rigby, J., Wheeler, B., Ballas, D., Thomas, B., Fahmy, E., Gordon, D. \& Lupton, R., Poverty, wealth and place in Britain, 1968 to 2005. The Policy Press for the Joseph Rowntree Foundation. http://www.jrf.org.uk/publications/poverty-and-wealth-across-britain1968-2005, 2007.

[18] Rose, D. and Pevalin, D.J., The National Statistics Socio-economic Classification: Origins, Development and Use, Institute for Social and Economic Research, University of Essex, Office for National Statistics, London, UK, 2005.

[19] Dorling, D., Personal communication to J.H. Barnes, Halford Mackinder Professor of Geography, University of Oxford, $9^{\text {th }}$ January 2015.

[20] Chatterton, T. and Barnes J.H., A social and spatial analysis of emissions from private vehicle use in Great Britain, Air Pollution XXVI, Proceedings of the 24th International Conference on Modelling, Monitoring and Management of Air Pollution, Crete Greece, 20-22 June 2016.

[21] Atkinson, R., The evidence on the impact of gentrification: new lessons for the urban renaissance? European Journal of Housing Policy, 4(1), 107-131, 2004.

[22] Defra, LAQM Technical Guidance, TG(16). Box 1.1, pp. 1-8, 2016.

[23] Department for Transport, Vehicle Emissions Testing Programme, Ref: ISBN 9781474131292, P002803657 04/16, Cm 9259, https://www.gov.uk /government/publications/vehicle-emissions-testing-programmeconclusions, 2016.

[24] Williams, B., Barnes, J.H., Chatterton, T.J., Hayes, E.T., Longhurst, J.W.S., A critical review of the robustness of the UK government's air quality plan and expected compliance dates, Air Pollution XXVI, Proceedings of the 24th International Conference on Modelling, Monitoring and Management of Air Pollution, Crete Greece, 20-22 June 2016. 